\title{
Impact of SYNTAX Score on In-hospital Outcome after Primary Percutaneous Coronary Intervention
}

\author{
Md. Shariful Islam¹, Md. Afzalur Rahman², Abdul Wadud Chowdhury ${ }^{3}$, Sayed Nasir Uddin4, Nupur Kar ${ }^{5}$, \\ Kajal Kumar Karmakar ${ }^{5}$, Mohammad Ullah Firoze ${ }^{6}$, Mohammad Arifur Rahman ${ }^{7}$, Monir Hossen Khan ${ }^{8}$, \\ Md. Nure Alam Ashrafi' ${ }^{1}$, Muhammad Ruhul Amin ${ }^{9}$, Md Minhaj Arefin ${ }^{1}$, Fathima Aaysha Cader ${ }^{10}$
}

\begin{abstract}
:
Background: Limited contemporary data exist regarding the impact of SYNTAX score on in-hospital outcomes undergoing primary percutaneous coronary intervention $(\mathrm{PCI})$ in acute STEMI patients.

Objectives: To evaluate the significance of the SYNTAX score for predicting in- hospital outcome after primary $\mathrm{PCl}$ in patient with acute STEMI.

Methods: This cohort study was conducted in the department of cardiology, National Institute of Cardiovascular Diseases, Dhaka, Bangladesh from September, 2015 to September, 2016. 42 patients with acute STEMI who underwent primary $\mathrm{PCl}$ were considered for the study. But 2 patients were excluded from the study due to failure of primary $\mathrm{PCI}$. The patients were divided into two groups: Group I (low SYNTAX score d"22) and Group II (high Syntax score > 22). The Syntax score of all patients were calculated from an initial coronary angiogram before primary $\mathrm{PCI}$. In-hospital outcome was observed in between two groups.
\end{abstract}

Results: Among traditional cardiovascular risk factors diabetes was significantly more prevalent in the Group
II than Group I ( $82.4 \%$ vs $34.8 \%$, p Â 0.003). Angiographic profile revealed maximum $(69.6 \%$ vs $17.6 \%)$ culprit lesion in LAD artery in Group I and maximum culprit lesion $(64.7 \%$ vs $21.7 \%)$ in RCA in Group II, these were the statistically significant between Group I and Group II (P<0.05). The high SYNTAX score group had lower TIMI $3(76.47 \%$ vs $91.3 \%$, p Â 0.03$)$ compared to the low SYNTAX score group. But there were no significant difference in complications as arrhythmia (2.5\% vs $0 \%)$, cardiogenic shock $(2.5 \%$ vs $0 \%)$, heart failure $(5 \%$ vs $\mathbf{2 . 5} \%$ ) and mortality (5\%vs $0 \%$ ) between high and low SYNTAX score. Multivariate logistic regression analysis revealed SYNTAX score (OR = 5.95, p Â 0.001) was an independent predictor of in-hospital outcome in patients under going primary $\mathrm{PCl}$. Performance test of SYNTEX score in the setting of Primary $\mathrm{PCl}$ outcome showed positive predictive value $83 \%$. Conclusions: SYNTAX score was an independent variable that can predict in-hospital outcomes of patients with acute STEMI undergoing primary $\mathrm{PCl}$.

Key wards : SYNTAX score, Primary PCI, STEMI

1. Assistant Registrar, Department of Cardiology, National Institute of Cardiovascular Diseases, Dhaka

2. Professor and Director, National Institute of Cardiovascular Diseases, Dhaka

3. Professor and Head, Department of Cardiology, Dhaka Medical College, Dhaka

4. Professor, National Institute of Cardiovascular Diseases, Dhaka

5. Associate Professor, Department of Cardiology National Institute of Cardiovascular Diseases, Dhaka

6. Associate Professor, Department of Cardiology, Manikganj Medical College, Manikganj

7. Junior Consultant, Department of Cardiology, National Institute of Cardiovascular Diseases, Dhaka

8. Registrar, Department of Cardiology, National Institute of Cardiovascular Diseases, Dhaka

9. Emergency medical officer, Shahid Ziaur Rahman Medical College Hospital, Bogra

10. Assistant Registrar, Department of Cardiology, Ibrahim Cardiac Hospital \& Research Institute, Dhaka.

Address of Correspondence: Dr Md Shariful Islam, Assistant Registrar, Department of Cardiology, National Institute of Cardiovascular Diseases, Dhaka., Mobile: +8801716424258, Email: mistyratan@gmail.com.

DOI: http://dx.doi.org/10.3329/bhj.v33i2.39308

Copyright (c) 2017 Bangladesh Cardiac Society. Published by Bangladesh Cardiac Society. This is an Open Access articles published under the Creative Commons Attribution-NonCommercial 4.0 International License (CC BY-NC). This license permits use, distribution and reproduction in any medium, provided the original work is properly cited and is not used for commercial purposes. 


\section{Introduction:}

Cardiovascular diseases account for more than 17 million deaths globally each year. This figure is to grow to 23.6 million by the year 2030. ${ }^{1}$ Estimates from the global burden of disease study suggests that by the year 2020 the South Asian part of the world (India, Pakistan, Bangladesh, Nepal) will have more individuals with atherosclerotic cardiovascular diseases than any other region. ${ }^{2}$

Primary $\mathrm{PCl}$ reduces the risk for mortality and subsequent myocardial infarction when compared with Thrombolytic therapy in patients with acute coronary syndromes. However, the invasive mechanical reperfusion strategies have their own complications. Major complications include death, MI, or stroke, and minor complications include transient ischemic attacks, vascular complications, contrast induced nephropathy, and angiographic complications.

Originally, the SYNTAX score was designed to grade the complexity of stable coronary artery disease. Higher values of this score, reflecting a more challenging coronary anatomy for the interventional cardiologist, also predict a worse prognosis after acute STEMI. ${ }^{3}$ Patients with very low predicted mortality could benefit from early discharge from the intensive care unit and from the hospital, resulting in better clinical care and optimization of health resources. In contrast, morbidity and mortality after STEMI are still high in other subgroups. ${ }^{4}$

The aim of the study is to investigate the usefulness of SYNTAX score in predicting outcome of primary $\mathrm{PCl}$ in acute STEMI patients in terms of severity and complexity of CAD.

\section{Methods:}

This prospective cohort study was conducted in the Department of Cardiology, National Institute of Cardiovascular Diseases, Dhaka, Bangladesh.from September, 2015 to September, 2016. The study included patients with acute STEMI who undergone primary $\mathrm{PCl}$ during the study period. Patients with valvular heart diseases, congenital heart diseases, prior thrombolytic therapy, prior $\mathrm{MI}, \mathrm{PCl}$ or $\mathrm{CABG}$ and severe comorbidities were excluded.

Proper medications was given in CCU. After adequate explanation Coronary angiogram (CA) was done by conventional method. Angiographic pattern and CAD severity assessment was done by visual estimation.

The SYNTAX scores of all patients were calculated by 2 independent experienced interventional cardiologists who were blinded to the identities. The patients were divided into 2 groups, those with low SYNTAX scores d"22 (Group I) and those with intermediate to high SYNTAX scores e"23 (Group II). ${ }^{5}$
Data analysis was performed using SPSS version 16 . Categorical variables were expressed as frequency and percentage and continuous variables as mean and standard deviation. Data was analyzed by student's t-test, chi-square test and Fisher exact test. Multivariate logistic regression analysis was done to assess the effect of independent variable and adjustment was done for confounding variable.

\section{Results:}

Total 42 patients with acute STEMI who underwent primary $\mathrm{PCl}$ were enrolled in this study. The main objective of the study was to determine impact of SYNTAX score for predicting In-hospital outcome after primary $\mathrm{PCl}$ in patients with acute STEMI. Two patients were excluded from this study due to primary PCI failure. In our study $57.5 \%$ were in SYNTAX score $\leq 22$ (Group I) and $42.5 \%$ were in SYNTAX score $>22$ (Group II).

The mean age \pm SD was $51.40 \pm 13.20$ years in Group I and $46.00 \pm 13.56$ years in Group II (Table I). The difference was not statistically significant. There are no significant difference of traditional cardiovascular risk factors among the Group I and Group II except DM which was statistically significant different in between two group. Angiographic profile (Table I) revealed maximum (69.6\% vs $17.6 \%$ ) culprit lesion in LAD artery in Group I and maximum culprit lesion $(64.7 \%$ vs $21.7 \%$ ) in RCA in Group II, these were the statistically significant between Group I and Group II ( $\mathrm{P}<0.05)$.

Group I= SYNTAX score $\leq 22$; Group II: SYNTAX score $>22$ $p$ value $>0.05^{\text {ns }}$

Regarding sex $69.5 \%$ and $30.5 \%$ patients were male and female in Group I and $88.2 \%$ and $11.8 \%$ were male and female in Group II respectively.

Angiographic outcome showed that $91.3 \%$ patient in Group I and $76.47 \%$ in Group II achieved TIMI flow 3 and the difference was statistically significant $(p=0.03)$. In Group I $8.7 \%$ patients and $11.76 \%$ patient in Group II achieved TIMI flow 2 and the difference was not statistically significant $(p=$ 0.8 ). No patient in Group I and $11.76 \%$ patient in Group II achieved TIMI flow 1 and the difference was not statistically significant $(p=0.14)$.

Complications of primary PCI in Group I Vs Group II: acute heart failure 2.5 . \% Vs $2.5 \%$ cardiogenic shock $00 \% \mathrm{Vs}$ $2.5 \%$ significant arrhythmia $00 \%$ Vs $2.5 \%$ and death $00 \%$ Vs 5\% and total in-hospital outcome: acute heart failure 5\%, cardiogenic shock $2.5 \%$, significant arrhythmia $2.5 \%$ and death $5 \%$ (Table III).

Multivariate analysis revealed that out of ten variable DM, ejection fraction and SYNTAX score were found to be the independently significant predictors outcome of the patients undergoing primary $\mathrm{PCl}$ with Odds ratio being 4.75 $(p=0.001), 1.71(p=0.01)$ and $5.95(p=0.001)$ respectively. 
Table-I

Distribution of age, cardiac risk factor and culprit vessel among the study patients

\begin{tabular}{|c|c|c|c|c|c|c|c|}
\hline \multirow{3}{*}{$\begin{array}{l}\text { Mean age } \pm S D \\
\text { Risk factors }\end{array}$} & \multirow{2}{*}{\multicolumn{2}{|c|}{$\begin{array}{c}\text { Group I }(n=23) \\
51.40 \pm 13.20\end{array}$}} & \multirow{2}{*}{\multicolumn{2}{|c|}{$\begin{array}{c}\text { Group II }(n=17) \\
46.00 \pm 13.56\end{array}$}} & \multirow{2}{*}{\multicolumn{2}{|c|}{ Total $(n=40)$}} & \multirow{3}{*}{$\begin{array}{l}p \text { value } \\
0.397^{\text {ns }}\end{array}$} \\
\hline & & & & & & & \\
\hline & No & $\%$ & No & $\%$ & No & $\%$ & \\
\hline Smoking & 13 & 56.5 & 14 & 82.4 & 27 & 67.5 & $0.085^{\mathrm{ns}}$ \\
\hline Hypertension & 14 & 60.9 & 11 & 64.7 & 25 & 62.5 & $0.804^{\mathrm{ns}}$ \\
\hline DM & 8 & 34.8 & 14 & 82.4 & 22 & 75.0 & $0.003^{s}$ \\
\hline Dyslipidemia & 11 & 47.8 & 13 & 76.5 & 24 & 60.0 & $0.068^{\mathrm{ns}}$ \\
\hline Family history of IHD & 5 & 21.7 & 6 & 35.3 & 11 & 27.5 & $0.343^{\mathrm{ns}}$ \\
\hline \multicolumn{8}{|l|}{ Culprit vessel } \\
\hline LAD & 16 & 69.6 & 3 & 17.6 & 19 & 47.5 & \\
\hline LCX & 2 & 8.7 & 3 & 17.6 & 5 & 12.5 & $0.014^{\mathrm{s}}$ \\
\hline RCA & 5 & 21.7 & 11 & 64.7 & 16 & 40.0 & \\
\hline
\end{tabular}

Data were analysis using chi-square and Fisher exact test

Group I= SYNTAX score $\leq 22$; Group II: SYNTAX score >22;

ns-not significant; s- significant

Table-II

Angiographic outcome between two groups according to TIMI flow after primary $\mathrm{PCI}(n=40)$

\begin{tabular}{|c|c|c|c|c|c|}
\hline \multirow[t]{2}{*}{ TIMI flow } & \multicolumn{2}{|c|}{ Group I $(n=23)$} & \multicolumn{2}{|c|}{ Group $\|(n=17)$} & \multirow[t]{2}{*}{$p$ value } \\
\hline & No & $\%$ & No & $\%$ & \\
\hline 0 & 0 & & 0 & & \\
\hline 1 & 0 & 0 & 2 & 11.76 & $0.14^{\mathrm{ns}}$ \\
\hline 2 & 2 & 8.7 & 2 & 11.76 & $0.8^{\text {ns }}$ \\
\hline 3 & 21 & 91.3 & 13 & 76.47 & $0.03^{s}$ \\
\hline
\end{tabular}

Data were analysis using chi-square test and Fisher exact test

Group I= SYNTAX score $\leq 22$; Group II: SYNTAX score $>22$

Table-III

Complications of study patients according to SYNTAX score $(n=40)$

\begin{tabular}{|c|c|c|c|c|c|c|c|}
\hline \multirow[t]{2}{*}{ Outcome } & \multicolumn{2}{|c|}{ Group I $(n=23)$} & \multicolumn{2}{|c|}{ Group II $(n=17)$} & \multicolumn{2}{|c|}{ Total } & \multirow[t]{2}{*}{$p$ value } \\
\hline & No & $\%$ & No & $\%$ & No & $\%$ & \\
\hline Acute heart failure & 1 & $2.5 \%$ & 1 & 2.5 & 2 & 5.0 & $0.863^{n s}$ \\
\hline Cardiogenic shock & 0 & 00 & 1 & 2.5 & 1 & 2,5 & $0.453^{n s}$ \\
\hline Significant arrhythmia & 0 & 00 & 1 & 2.5 & 1 & 2.5 & $0.453^{n s}$ \\
\hline Death & 0 & 00 & 2 & 5.0 & 2 & 5.0 & $0.371^{\mathrm{ns}}$ \\
\hline
\end{tabular}

Data were analysis using chi-square test and Fisher exact test Group I= SYNTAX score $\leq 22$; Group II: SYNTAX score >22 
Table-IV

Multivariate logistic regression analysis of determinants including SYNTAX score that affect the outcome of patients undergoing primary $\mathrm{PCl}(n=40)$

\begin{tabular}{lllllll}
\hline & Beta & S.E & p value & OR & \multicolumn{2}{c}{$95 \% \mathrm{Cl}$} \\
& & & & & Lower & Upper \\
\hline Age & 0.379 & 0.793 & 0.632 & 0.684 & 0.144 & 3.240 \\
Sex & 0.973 & 0.890 & 0.274 & 0.378 & 0.066 & 2.162 \\
Smoking & 1.278 & 0.763 & 0.094 & 0.279 & 0.062 & 1.242 \\
Hypertension & 0.405 & 0.527 & 0.442 & 0.667 & 0.321 & 4.326 \\
DM & 2.169 & 0.772 & $0.001^{\mathrm{s}}$ & 4.750 & 1.926 & 9.754 \\
Dyslipidemia & 0.956 & .0 .677 & 0.158 & 2.600 & 0.689 & 9.806 \\
Family history & 1.052 & 0.734 & 0.152 & 0.349 & 0.083 & 1.473 \\
Creatinine & 0.091 & 0.376 & 0.809 & 0.913 & 0.437 & 1.909 \\
LVEF & 1.702 & 0.699 & $0.015^{\mathrm{s}}$ & 1.714 & 0.046 & 2.717 \\
SYNTAX score & 2.973 & 1.132 & $0.001^{\mathrm{s}}$ & 5.955 & 2.216 & 19.839 \\
\hline
\end{tabular}

s- significance

\section{Discussion:}

There are few literatures regarding the usefulness of the SYNTAX score for predicting in-hospital outcome after primary percutaneous coronary intervention in patient with acute STEMI.

We found diabetes to increase the risk of MACE in patients who received primary $\mathrm{PCI}$ for acute STEMI. In other words, diabetes was significantly more prevalent in the Group II. Various studies have also highlighted the short term (during hospitalization and the first year after the disease) and long term effects of diabetes on the MACE. 6,7 Diabetes can thus be considered as a risk factor for MACE after primary PCI.

In this study, smoking did not have any negative effects on MACE. However, a previous research reported better reperfusion rate after primary $\mathrm{PCl}$ in smokers ${ }^{8}$ High arterial blood pressure is a risk factor for coronary artery disease and increases the risk of complications after acute coronary syndrome. 9,10 However, we did not find significant differences in level of blood pressure between the two groups. Hyperlipidemia is a risk factor for coronary artery disease, it has no significant effects on the incidence of MACE in our study. Some studies have identified high levels of lipoprotein (a) to be associated with poor outcome in patients with acute myocardial infarction. ${ }^{11}$

Angiographic profile in our study showed that left anterior descending (LAD) artery was the most common (47.5\%) culprit vessel followed by right coronary artery (RCA) was $40 \%$ and left circumflex artery (LCX) was $12.5 \%$. These were similar to the finding (LAD 51.2\%, RCA 38.5\% and LCX 10.2\%). ${ }^{12}$ In this study we found cardiogenic shock $2.5 \%$, acute heart failure $5 \%$ and death $5 \% .{ }^{13}$ reported that cardiogenic shock developed in $3.4 \%$ post-randomization, and mortality at 90 days was $54.6 \%$. Congestive heart failure occurred in $4.4 \%$ which are also compatible with our study. ${ }^{14}$

TIMI flow is one of the important factor in determining the outcome of primary PCI in patient with acute STEMI. In our study, TIMI 3 flow was established among $91.3 \%$ patients in Group I and $76.47 \%$ in Group II. Some study found similar finding (87.5\%). ${ }^{12}$ Multiple regression analysis showed that DM, LVEF and SYNTAX score are independent predictors of adverse in-hospital outcome following primary $\mathrm{PCl}$ (OR=4.75, 1.71 \& 5.95, respectively). Another author also found Killip class and SYNTAX score $(\mathrm{OR}=1.12 \& 1.08)$ as the predictors of in-hospital adverse outcome. ${ }^{15}$

\section{Conclusion:}

This study demonstrates that a high SYNTAX score before Primary PCI provides important prognostic information with regards to in-hospital clinical outcomes including mortality. In our acute STEMI cohort, risk of mortality was notably increased during the early periprocedural period. The SYNTAX score can be used for risk stratification in patients undergoing primary $\mathrm{PCl}$.

\section{Limitations:}

Interpretation of angiograms and assessment of the SYNTAX score was not performed by QCA. Although the result of the study supports the hypothesis there were several limitations such as coronary angiogram was evaluated by visual estimation. So there was chance of interobserver and intraobserver variation to calculate the SYNTAX score. The study was carried out only in single centre, study period was short, sample size was small and it was a non randomized study.

\section{Conflict of interest- None.}




\section{References}

1. Wong ND. Epidemiological studies of CHD and the evolution of preventive cardiology. Nature Reviews Cardio. 2014; 11: 276-289.

2. Chakraborty B, Zaman F and Sharma AK. Combating Coronary Artery Disease in South Asia -What is special? Bangladesh J of Cardio.2009; 01: 088- 090.

3. Garg S, Sarno G, Serruys PW, Rodriguez AE, Bolognese L. and Anselmi M, STRATEGY and MULTISTRATEGY Investigators. Prediction of 1-year clinical outcomes using the SYNTAX score in patients with acute ST-segment elevation myocardial infarction undergoing primary percutaneous coronary intervention: a substudy of the STRATEGY (Single High-Dose Bolus Tirofiban and Sirolimus-Eluting Stent Versus Abciximab and Bare-Metal Stent in Acute Myocardial Infarction) and MULTISTRATEGY (Multicenter Evaluation of Single High-Dose Bolus Tirofiban Versus Abciximab With Sirolimus-Eluting Stent or Bare- Metal Stent in Acute Myocardial Infarction Study) trials. J Am Coll Cardiol Intv. 2011; $4(\mathrm{I}): 66-75$.

4. Goldberg RJ, Spencer FA, Gore JM, Lessard D and Yarzebski J. Thirty-year trends (1975 to 2005) in the magnitude of, management of, and hospital death rates associated with cardiogenic shock in patients with acute myocardial infarction: a population-based perspective. Circ. 2009; 119: 1211-1219.

5. Scherff F, Vassalli G, Siirder D, Mantovani A, Corbacelli C, Pasotti E, Klersy C, Auricchio A, Moccetti T and Pedrazzini GB. The SYNTAX score predicts early mortality risk in the elderly with acute coronary syndrome having primary PCI. J Invasive Cardiol. 2011; 23(12): 505-10.

6. Gasior M., Pres D, Stasik-Pres G, Lech P, Gierlotka $M$ and Lekston A. 2008. Does glucose level at hospital discharge predict one-year mortality in patients with diabetes mellitus treated with percutaneous coronary intervention for ST-segment elevation myocardial infarction? Kardiol Pols. 2008; 66(1): 1-8.

7. Banning AP, Westaby S, Morice MC, Kappetein AP, Mohr FW and Berti S. Diabetic and nondiabetic patients with left main and/or 3-vessel coronary artery disease: comparison of outcomes with cardiac surgery and paclitaxel-eluting stents. JAm Coll Cardiol. 2010; 55(11): 1067-75.
8. Albertal M, Cura F, Escudero A G, Thierer J, Trivi M and Padilla L T. Mechanism Involved in the Paradoxical Effects of Active Smoking Following Primary Angioplasty: A Subanalysis of The

1. Protection of Distal Embolization in High-Risk Patients With Acute Myocardial Infarction Trial. J Cardiovas Med (Hagerstown). 2008; 9(8): 810-2.

9. Ali WM, Zubaid M, El-Menyar A, Al MW, Al-Lawati, J and Singh $\mathrm{R}$. The prevalence and outcome of hypertension in patients with acute coronary syndrome in six Middle-Eastern countries. Blood Pressu. 2011; 20(1): 20-6.

10. Picariello C, Lazzeri C, Attana P, Chiostri M, Gensini GF and Valente $S$. The impact of hypertension on patients with acute coronary syndromes. International J Hyperten. 2011; 56: 36-57.

11. Cho JY, Jeong MH, Ahn Y, Hong YJ, Park HW and Yoon NS. High Lipoprotein(a) Levels are associated With Long-Term Adverse Outcomes in Acute Myocardial Infarction Patients in High Killip Classes. Korean Cir J. 2010; 40(10): 491-8.

12. Salim MA. Malik F, Ahmed N, Badiuzzaman M, Khan R J, Haque KMHSS and Malik A. In-hospital outcome of primary percutaneous coronary intervention for the management of acute ST-segment elevation myocardial infarction in a Bangladeshi population. Globalheart, 2010; 5, 1: 23-26.

13. French JK, Armstrong PW, Cohen E and Kleiman NS. Cardiogenic shock and heart failure postpercutaneous coronary intervention in ST-elevation myocardial infarction: Observations from "Assessment of Pexelizumab in Acute Myocardial Infarction". Am Heart J. 2011; 89-97.

14. Uddin MJ, Khalil I, Karmakar K, Kabir H, Litu RI, Choedhury AHK, Majumder AAS, Khair A, Hasan A, Kabir S. 2013. Outcome of primary percuntaneous coronary intervention (PCI) in NICVD, Dhaka, Bangladesh- Our Initial Experience. University Heart. 2013; 9: 83-87.

15. Ay9a B, Akin F, Celik o, getin S, §ahin I, GUI§en K, KalyoncuogHu M, Katkat F, Okuyan E and Din9kal MH. Does SYNTAX score predict in-hospital outcomes in patients with ST elevation myocardial infarction undergoing primary percutaneous coronary intervention? Kardiol Pols, 2014; 72(9): 806-813. 